\title{
Effect of some tropical eggplant fruits (Solanum Spp) supplemented diet on diabetic neuropathy in male Wistar rats in- vivo
}

\author{
Esther E. Nwanna*, Emmanuel O. Ibukun and Ganiyu Oboh
}

Functional food, Nutraceuticals and Phytomedicine, Department of Biochemistry, Federal University of Technology, P.M.B 704 Akure, Nigeria

*Corresponding author: Esther E. Nwanna, PhD, Functional food, Nutraceuticals and Phytomedicine, Department of Biochemistry, Federal University of Technology, P.M.B 704 Akure, Nigeria

Submission Date: September 6, 2016, Accepted Date: October 27, 2016, Publication Date: October 30, 2016

Citation: Nwanna E.E., Ibukun E.O., and Oboh G. Effect of some tropical eggplant fruits (Solanum Spp) supplemented diet on diabetic neuropathy in male Wistar rats in-vivo. Functional Foods in Health and Disease 2016; 6(10):661-676

\begin{abstract}
Background: Eggplant is a popular crop grown in the subtropics and tropics for its fruits. Although it is a perennial plant, its fruits are grown commercially as an annual crop. The fruit is primarily used as a vegetable for various dishes. The eggplant has various kinds of species, which are highly variable in color, shape, and size.
\end{abstract}

Content and Purpose of this study: This study focused on comparing the effect of dietary tropical eggplants Solanum kumba (PG) Solanum gilo (PW) and Solanum aethiopicum (PGW) species. Type-II-Diabetes was induced experimentally by high fat fed/low dose streptozotocin (STZ) $35 \mathrm{mg} / \mathrm{kg}$ body weight on male wistar rats. The diabetic subjects were fed diets supplemented with 20-40\% eggplant fruits of different species for 14 days. The effect of the diets on the blood glucose level, pancreatic $\alpha$-amylase, intestinal $\alpha$-glucosidase and angiotensin-I-converting enzyme (ACE) activities, plasma antioxidant status were determined, in addition to the quantification of the fruits polyphenols using High Performance Liquid Chromatography/ diode array detection fingerprinting (HPLC/DAD).

Results: The results revealed that there was no significant $(P<0.05)$ difference in the average feed intake in all the groups. Supplementation with eggplant diet gradually reduced blood glucose level and hypertension in the diabetic rats (treatment groups) when compared to diabetic rats (negative control) without treatment and metformin-treated (positive control group). The treated group with eggplant diet demonstrated elevated levels of antioxidant status such as glutathione peroxidase GPX, glutathione transferase GST, reduced glutathione GSH, Catalase and Ascorbic acid. The supplemented diet reduced the free radicals produced as typified (TBARS). 
Conclusion: This study showed that the eggplant may attenuate hyperglycemia, hypertension and oxidative stress in the type-2-diabetes condition with Solanum kumba having the highest activity, which is not far fetched due to its synergistic activities of polyphenols as revealed in the HPLC/DAD analysis.

Keywords: Solanum spp, Polyphenols, Diabetes, Enzymes, HPLC/DAD analysis

\section{INTRODUCTION}

Type II Diabetes Mellitus (DM II) is a chronic progressive condition which is marked by hyperglycemia, usually due to either hypoinsulinemia or insulin resistance [1]. Currently, 285 million people are affected with DM II worldwide; this number is expected to reach 439 million by the year 2030 [2]. Long standing DM is associated with macro and microvasculature abnormalities [3], pathological changes of neurons, skin, blood vessels and lens [4, 5] leading to hypertension, end stage renal failure, blindness and neuropathies [4]. The degree of hyperglycemia and duration of diabetes are often linked with the development of these complications. Millions of people in developing nations, such as sub-sahara Africa, have resorted to the use of plants to treat or manage their ailments; this could be due to the high cost of orthodox health care or the global shift towards the use of natural sources rather than synthetic drugs [6]. Gardenegg or Eggplant is an edible fruits vegetable crop belonging to the family Solanaceae. The family is one of the largest and most important families of vegetable which are tropical in origin. The eggplant species have been in use in traditional medicine systems for the management of diabetes and the National Diabetes Education Programme of National Institute of Health, the Mayo Clinic and American Diabetes Association [7] has also recommended the eggplant as a choice plant-fruit in managing the degenerative condition [7, 8]. There are different species of the eggplant (Solanum spp), endowed in Nigeria. Invitro studies have been done recently on some species [9]. In continuation of the research, studies were undertaken on their invivo activities in order to assess the effect of these tropical eggplant fruits diet on $\alpha$-amylase, $\alpha$-glucosidase and angiotensin-I converting enzyme activities in high fat diet/STZ induced diabetic rat model; with the aim of providing the possible rationale underlying the antidiabetic properties of eggplant which could served as a functional food.

\section{MATERIALS AND METHODS}

Fresh and matured eggplant (Solanum kumba, Solanum gilo and Solanum aethiopicum) species were sourced from a farm settlement in Ondo State, Nigeria. Authentication of the samples were carried out at the Department of Biology, Federal University of Technology, Akure, Nigeria. The eggplant species were air-dried and ground into fine powder using a laboratory mill until they could pass through a $1.0 \mathrm{~mm}$ screen. .

Chemicals and reagents: High-performance liquid chromatography (HPLC)-grade methanol, acetic acid, gallic acid, caffeic acid and ellagic acid etc were purchased from Merck (Darmstadt, Germany). Streptozotocin (Art. No. SO-130), quercetin, isoquercitrin, quercitrin, rutin and kaempferol were acquired from Sigma-Aldrich ChemicalCo. (St Louis, MO, USA). Disodium hydrogen phosphate(Na2HPO4), sodium dihydrogen phosphate (NaH2PO4), ethylacetate, hydrochloric acid $(\mathrm{HCl})$ and sodium chloride $(\mathrm{NaCl})$ were obtained from BDH Merck Ltd (Poole, UK).Protein test kits were obtained from Randox Laboratories Ltd (Ardmore, Crumlin, UK). Dinitrosalicylic acid (DNSA), potato starch, hippuryl histidyl leucine 
(HHL) and $p$-nitrophenyl-_-D-glucopyranoside (PNP) were sourced from Sigma-Aldrich, Chemie GmbH (Steinheim, Germany). Blood glucose test strips for Finetest glucometer and metformin were purchased from Matador Pharmaceutical Ltd (Akure, Ondo State,Nigeria).

Experimental design: Feed formulation and bioassay were carried out according to the modified methods used in the studies conducted Oboh G. and Ogunruku O.O. [10] and Srinivasan K., Viswanad B., Asrat L., Kaul C.L. and Ramarao P. [11] respectively. Fifty-four male Wistar rats weighing 180-200g were purchased from the Department of Veterinary Medicine, University of Ibadan, Nigeria. The rats were acclimatized for a period of 2 weeks. The animals were kept in wire-mesh cages under a controlled light cycle ( $12 \mathrm{~h}$ light/12 h dark) and placed on commercially available feed and water administered ad libitum during the period of acclimatization. A total of 54 rats were used for this study. The animals were allocated with two dietary regimens, 6 rats were fed with only the basal diet $(44.4 \%$ skimmed milk, $41.6 \%$ corn flour, $10 \%$ oil and $4 \%$ mineral/primary premix) and the remaining 48 rats were fed with a high fat diet (HFD) (44.4\% skimmed milk, $21.6 \%$ corn flour, 30\% lard and 4\% mineral/primary premix) for an initial period of 2 weeks.

Animal ethics: All of the animals received humane care according to the criteria outlined in the Guide for the Care and the Use of Laboratory Animals prepared by the National Academy Science and published by the National Institute of Health (USA). The ethic regulations have been followed in accordance with national and institutional guidelines for the protection of animals' welfare during experiments. The experiment was carried out at the Functional Food, Nutraceuticals and Phytomedicine Laboratory in the Department of Biochemistry, Federal University of Technology, Akure, Ondo State, Nigeria.

Development of HFD fed/STZ-induced diabetic rat model: The 54 rats fed with HFD were fasted for $12 \mathrm{~h}$ and a single intraperitoneal injection of STZ (35 mg/kg body wt.) freshly prepared in citrate buffer $(0.1 \mathrm{M}, \mathrm{pH} 4.5)$ was administered [12]. Animals with fasting blood glucose $\geq 200 \mathrm{mg} / \mathrm{dl}, 72 \mathrm{~h}$ after STZ administration were considered diabetic and used for this experiment.

Experimental design: The animals were randomly divided into seven (9) groups of six (6) animals each. Group A, normal rats received citrate buffer $(\mathrm{pH} 4.5)(1 \mathrm{~mL} / \mathrm{kg}$, i.p.) and fed with basal diet only. The Group B diabetic rats were fed with basal diet only. Group C diabetic rats $(35 \mathrm{mg} / \mathrm{kg}$ body wt.STZ received $100 \mathrm{mg} / \mathrm{kg}$ i.p metformin orally/day and fed with basal diet only. Group D diabetic rats were fed with basal diet supplemented with $20 \%$ Solanum gilo (PW). Group E diabetic rats fed with diet supplemented with $40 \%$ Solanum gilo (PW). Group F diabetic rats fed with diet supplemented with $20 \%$ Solanum kumba (PG). Group G diabetic rats fed with diet supplemented with 40\% Solanum kumba (PG). Group H diabetic rats fed with diet supplemented with $20 \%$ Solanum aethiopicum (PGW). Group I diabetic rats fed with diet supplemented with $40 \%$ Solanum aethiopicum (PGW). The experiment lasted for 14 days; throughout the duration of the study, all animals remained on the assigned diet.

Preparation of tissue homogenates: Animals were sacrificed after an overnight fast by cervical dislocation and blood was rapidly collected by direct heart puncture. The pancreas, liver, lung, and small intestine were isolated, rinsed in $1.15 \% \mathrm{KCl}$, blotted with filter paper and 
then weighed. The small intestine were minced with scissors in 3 volumes of ice-cold $0.1 \mathrm{~mol}$ $\mathrm{L}^{-1}$ phosphate buffer ( $\mathrm{pH}$ 6.9). The pancreas was cut into small pieces with the aid of scissors in 3 volumes of $200 \mathrm{mmol} \mathrm{L}-1$ sodium phosphate buffer ( $\mathrm{pH} 6.9$ with $6 \mathrm{mmol} \mathrm{L}-1 \mathrm{NaCl}$ ) and the lung was sliced into fragments in 3 volumes of $125 \mathrm{mmol} \mathrm{L}-1$ Tris- $\mathrm{HCl}$ buffer $(\mathrm{pH} 8.3$ ) and homogenized in a Potter-Elvehjem homogenizer. The homogenates were later centrifuged at $12000 \times g$ for $15 \mathrm{~min}$ at $4{ }^{\circ} \mathrm{C}$ to obtain the post-mitochondrial fraction (PMF), which was stored at $4{ }^{\circ} \mathrm{C}$ and later used for biochemical assays.

Analytical procedure: Plasma lipid peroxidation was estimated using the thiobarbituric acid (TBA) reaction with thiobarbituric acid reactive species (TBARS) as a product formed during the peroxidation of lipid membrane [13]. Glutathione-S-transferase (GST) activity was estimated according to the method of Mannervik and Guthenberg [14]. Glutathione (GSH) content was determined by the method of Ellman [15]. The pancreas was assayed for the $\alpha$ amylase activity [16], the small intestine was assayed for $\alpha$-glucosidase activity [17], and the lung was assayed for the ACE activity [18].

\section{Quantification of compounds by HPLC-coupled with diode array detection (DAD):} Reverse phase chromatographic analyses were carried out under gradient conditions using a C18 column $(4.6 \mathrm{~mm} \times 150 \mathrm{~mm})$ packed with $5 \mu \mathrm{m}$ diameter particles. The mobile phase was water containing $2 \%$ acetic acid (A) and methanol (B), and the composition gradient was $5 \%$ of B until 2 min, and then changed to obtain $25 \%, 40 \%, 50 \%, 60 \%, 70 \%$ and $100 \%$ B at 10, 20, 30, 40, 50 and $60 \mathrm{~min}$ respectively following the method described by [19] with slight modifications. All the samples were analyzed at a concentration of $20 \mathrm{mg} / \mathrm{mL}$. The presence of eleven antioxidants compounds was investigated, namely, gallic acid, caffeic acid, ellagic acid, chlorogenic acid, kaempferol, catechin, epicatechin, quercetin, quercitrin, isoquercitrin,

and rutin. Identification of these compounds was performed by comparing their retention time and UV absorption spectrum with those of the commercial standards. The flow rate was 0.7 $\mathrm{ml} / \mathrm{min}$, injection volume $40 \mu \mathrm{l}$ and the wavelength were $254 \mathrm{~nm}$ for gallic acid, $280 \mathrm{~nm}$ catechin and epicatechin, $327 \mathrm{~nm}$ for caffeic, ellagic acid and chlorogenic acids, and $365 \mathrm{~nm}$ for quercetin, quercitrin, isoquercitrin, kaempferol and rutin. The samples and mobile phase were filtered through a $0.45 \mu \mathrm{m}$ membrane filter (Millipore) and then degassed by an ultrasonic bath prior to use. Stock solutions of standards references were prepared in the HPLC mobile phase at a concentration range of $0.020-0.200 \mathrm{mg} / \mathrm{ml}$ for quercetin, quercitrin isoquercitrin, kaempferol rutin, catechin and epicatechin; and $0.050-0.250 \mathrm{mg} / \mathrm{ml}$ for chlorogenic, ellagic acid, caffeic and gallic acids. The chromatography peaks were confirmed by comparing its retention time with those of reference standards and by DAD spectra (200 to $500 \mathrm{~nm}$ ). All chromatography operations were carried out at ambient temperature and in triplicate. The limit of detection (LOD) and limit of quantification (LOQ) were calculated based on the standard deviation of the responses and the slope using three independent analytical curves, as defined in the study conducted [20].

\section{DATA ANALYSIS}

Data are presented as Mean \pm standard deviation (SD), and were analyzed by one-way ANOVA followed by Tukey's multiple comparison using SPSS 17.0 software for Windows. Differences were considered statistically significant at $p<0.05$ [21]. 


\section{RESULTS}

Here in Figure 1, the effect of diets supplemented with Solanum spp on the blood glucose levels in diabetic rats is depicted. The study revealed a significantly $(\mathrm{P}<0.05)$ higher blood glucose level in the diabetic control rats (Group B) than in the normal rats (Group A). However, treatment with metformin (Group C) and diets supplemented with eggplant diets (Groups D-I) caused a significant $(\mathrm{P}<0.05)$ decrease in the blood glucose levels of the diabetic rats when compared with the animals in Group B. Furthermore, between day 1 and day 7 of the study, a sharp decrease in the blood glucose level was observed in the metformin (Group C). However, there was a decease in blood glucose level that was observed between days 7 and 10 for other groups of treated animals.

\section{Day 1 Day 5 Day 9 Day 14}

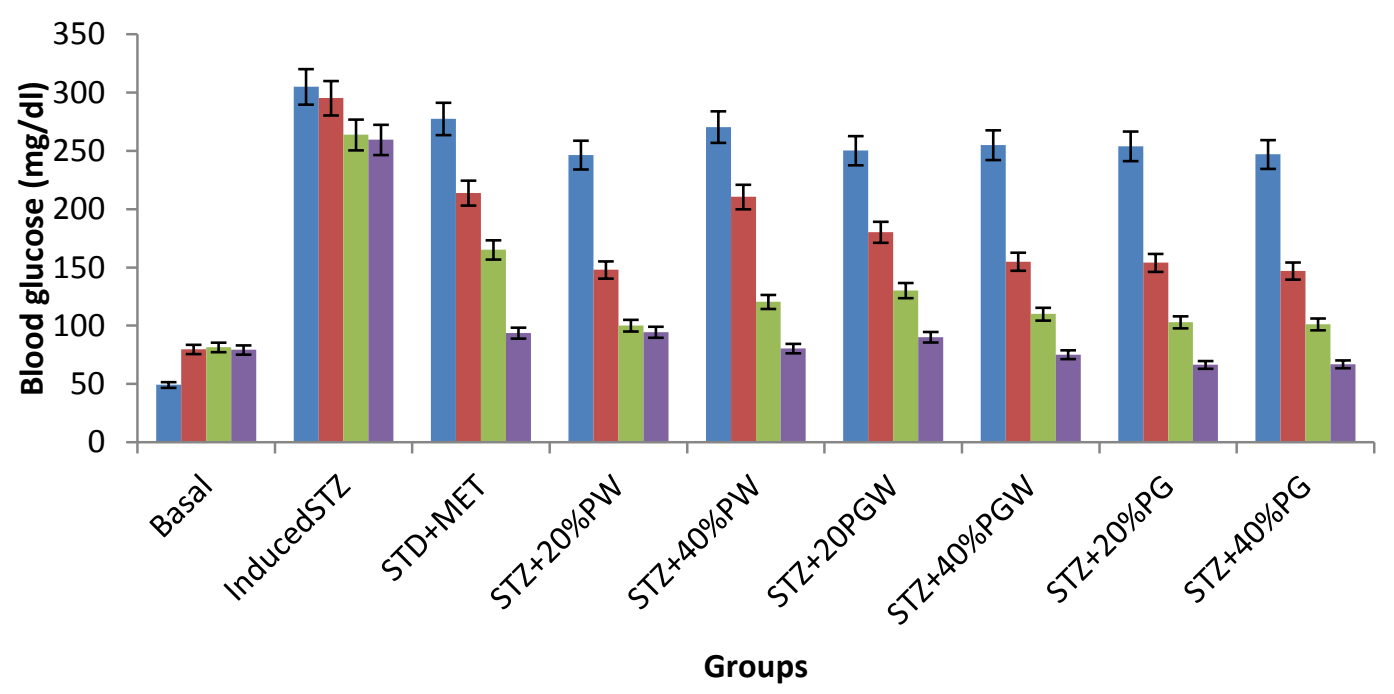

Figure 1: The effect of diets supplemented with Solanum spp on blood glucose level in HFD/low dose STZ-induced diabetic rats $(35 \mathrm{mg} / \mathrm{kg}$ bwt). Values represent mean \pm standard deviation $(\mathrm{n}=6)$. Key: Group A: normal rats received citrate buffer $(\mathrm{pH} 4.5)(1 \mathrm{~mL} / \mathrm{kg}$ i.p) and fed with basal diet only. Group B: diabetic rats fed with basal diet only. Group C: diabetic rats received $100 \mathrm{mg} / \mathrm{kg}$ orally metformin and fed with basal diet only. Group D: diabetic rats fed with basal diet supplemented with $20 \%$ Solanum gilo (PW). Group E: diabetic rats fed with diet supplemented with $40 \%$ Solanum gilo (PW),. Group F: diabetic rats fed with diet supplemented with 20\% Solanum kumba (PG). Group G diabetic rats fed with diet supplemented with $40 \%$ Solanum kumba (PG). Group H diabetic rats fed with diet supplemented with 20\% Solanum aethiopicum (PGW). Group I diabetic rats fed with diet supplemented with $40 \%$ Solanum aethiopicum (PGW). The experiment lasted for 14 days and throughout the duration of the study; all animals remained on the assigned diet.*P $<0.05$ compared to Group I and ${ }^{\#} \mathrm{P}<0.05$ compare Group II to other groups.

Effect of eggplant diet (Solanum spp) on $\alpha$-amylase and $\alpha$-glucosidase activities in diabetic rats: The inhibition of carbohydrate hydrolyzing enzymes such as $\alpha$-amylase and $\alpha$ glucosidase has been suggested to be one practical approach to the control of hyperglycemia in diabetic situations. Thus, the effects of diets supplemented with eggplant diet on pancreatic $\alpha$ amylase and intestinal $\alpha$-glucosidase activities in the diabetic rats are presented in Figures 2 and 3 respectively and Table 1 . The result revealed a significant $(\mathrm{P}<0.05)$ increased in both the $\alpha$-amylase and $\alpha$-glucosidase activities in the diabetic control rats (Group B) when compared to the normal rats (Group A). However, treatment with metformin (Group C) and eggplant diets supplemented (Groups D-I) resulted in a significant $(\mathrm{P}<0.05)$ decreased in the 
activities of both enzymes in the diabetic rats to values close to the normal rats, with Solanum kumba diet demonstrating the best output followed by Solanum aethiopicum diet.

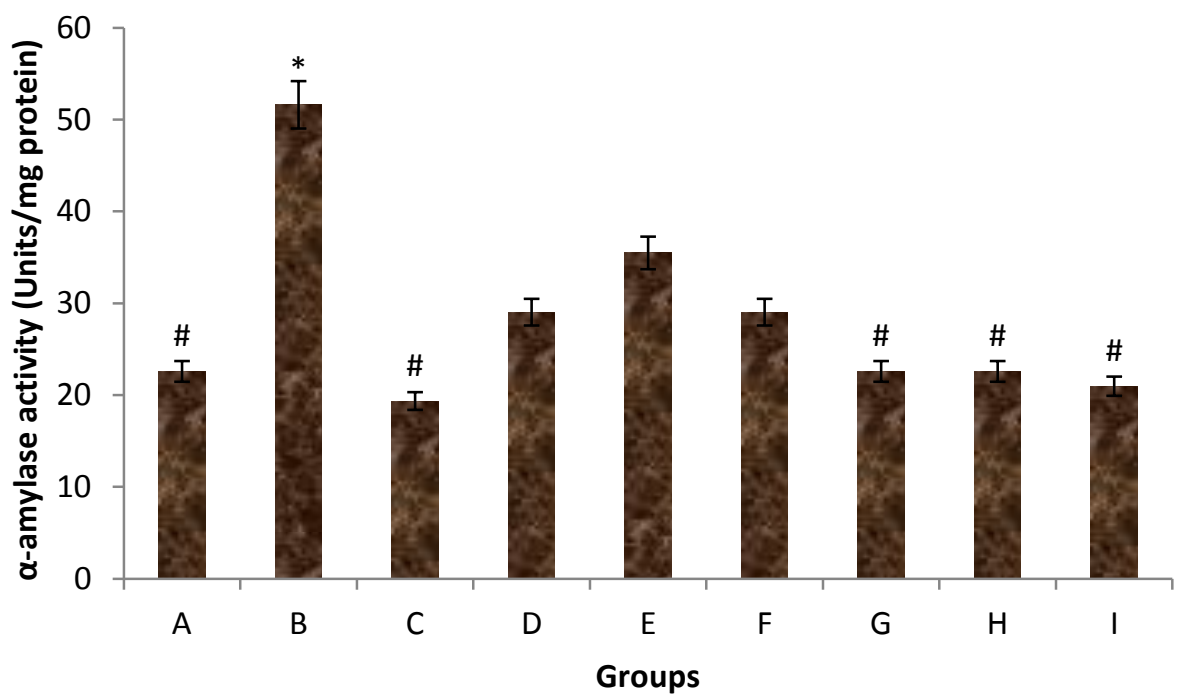

Figure 2. The effect of dietary Solanum spp on pancreatic $\alpha$-amylase activity in type 2 diabetic rats. Values represent mean \pm standard deviation $(n=6)$. Bars with the same superscript symbol $\left({ }^{\#}\right)$ are not significantly different $(P<0.05)$. KEY: A: Control B: Induced with STZ C: Induced + Metformin D: Induced $+20 \% \mathrm{PW}$

E: Induced $+40 \%$ PW F: Induced $+20 \%$ PGW G: Induced $+40 \%$ PGW H: Induced $+20 \%$ PG I: Induced $+40 \%$ PG

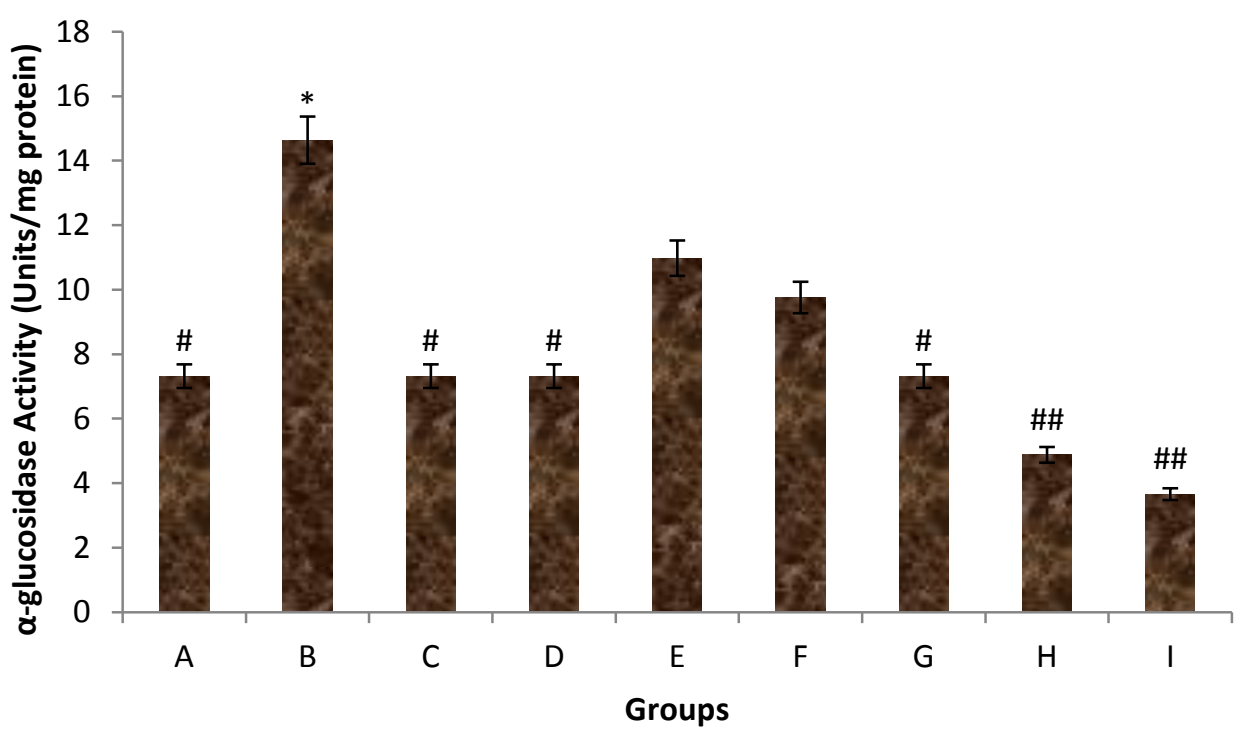

Figure 3. The effect of dietary Solanum spp on intestinal $\alpha$-glucosidase activity in type 2 diabetic rats. Values represent mean \pm standard deviation $(n=6)$. Bars with the same superscript symbol $(\#)$ are not significantly different $(P<0.05)$. KEY: A: Control B: Induced with STZ C: Induced + Metformin D: Induced $+20 \%$ PW E: Induced + 40\% PW F: Induced + 20\% PGW G: Induced + 40\% PGW H: Induced $+20 \%$ PG I: Induced $+40 \%$ PG

Effect of eggplant diets on ACE activity in diabetic rats: Figure 4 and Table 1 represent the effect of eggplants diets on ACE activity in diabetic rats. As revealed by the result, a significant $(\mathrm{P}<0.05)$ increased in the ACE activity was observed in diabetic control rats (Group B) when compared to the normal rats (Group A). Nevertheless, treatment with 
metformin (Group C) and treated with eggplant (Groups D-I) caused a significant $(\mathrm{P}<0.05)$ decreased in ACE activity in the diabetic rats. However, despite the decreased in ACE activity brought about by the various treatments, only diabetic rats treated with with Solanum kumba (Groups I) had their ACE activity decreased to a level close to/lower than that recorded for normal rats followed by Solanum aethiopicum diet.

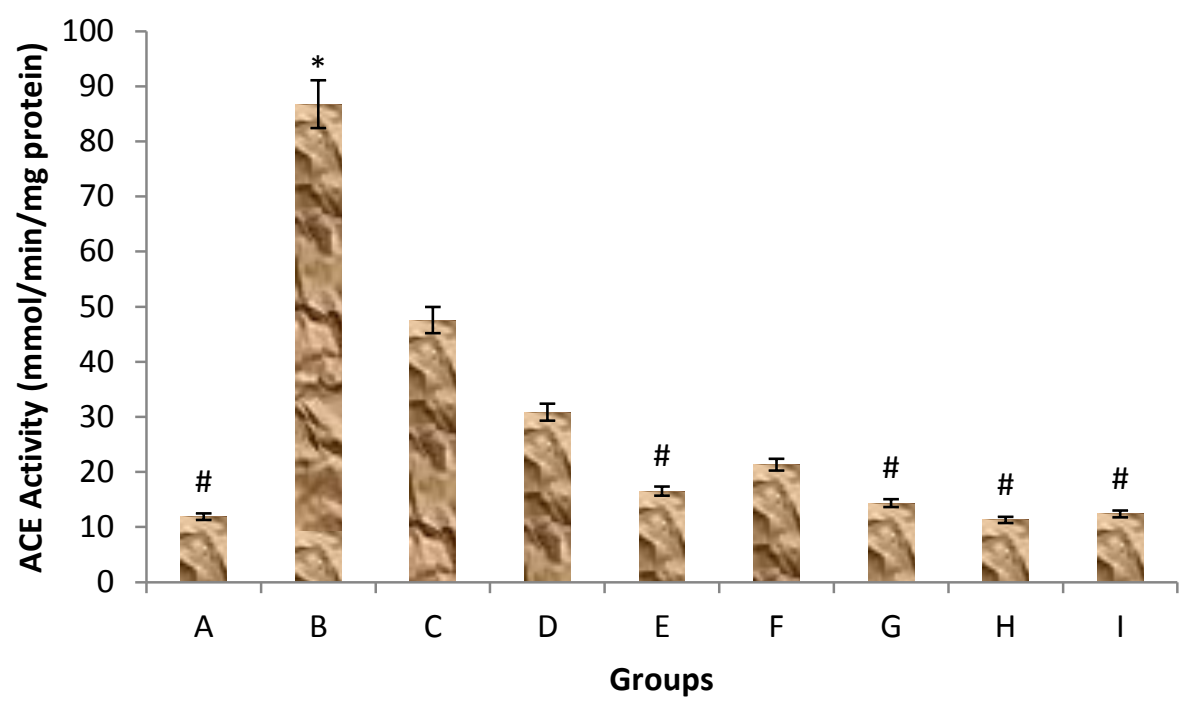

Figure 4. The effect of dietary Solanum spp on lung in angiotensin-1-converting enzyme activity in type 2 diabetic rats. Values represent mean \pm standard deviation $(n=6)$. Bars with the same superscript symbol (\#) are not significantly different $(P<0.05)$. KEY: A: Control B: Induced with STZ C: Induced + Metformin D: Induced + 20\% PW E: Induced + 40\% PW F: Induced + 20\% PGW G: Induced $+40 \%$ PGW H: Induced $+20 \%$ PG I: Induced $+40 \%$ PG

Table 1: The effect of dietary eggplant powder on the antioxidant status and enzymes in type-2 diabetic rats

\begin{tabular}{|c|c|c|c|c|c|}
\hline Groups & Treatments & MDA & a-amylase & a-glucosidase & $\mathrm{ACE}$ \\
\hline & \multicolumn{2}{|c|}{ (unit/mg protein) } & \multicolumn{3}{|c|}{ (mmol/min/mgprotein) } \\
\hline A & Basal (control) & $6.76 \pm 2.04$ & $22.58 \pm 2.6^{\#}$ & $7.32 \pm 1.05^{\#}$ & $11.80 \pm 3.23^{\#}$ \\
\hline B & Induced STZ & $19.45 \pm 3.01$ & $51.61 \pm 4.31$ & $14.63 \pm 2.01$ & $86.70 \pm 5.46$ \\
\hline $\mathrm{C}$ & Induced+ Metformin & $11.76 \pm 3.02$ & $19.35 \pm 2.80^{\#}$ & $7.32 \pm 3.05^{\#}$ & $47.50 \pm 3.34$ \\
\hline $\mathrm{D}$ & Induced + 20\%PW & $8.86 \pm 2.07^{\#}$ & $29.03 \pm 2.97$ & $7.32 \pm 3.05^{\#}$ & $30.80 \pm 2.99$ \\
\hline $\mathrm{E}$ & Induced $+40 \% \mathrm{PW}$ & $9.96 \pm 3.03^{\#}$ & $35.45 \pm 3.42$ & $10.98 \pm 3.42$ & $16.50 \pm 1.25$ \\
\hline $\mathrm{F}$ & Induced $+20 \%$ PG & $9.96 \pm 3.03^{\#}$ & $29.03 \pm 2.95^{\#}$ & $9.76 \pm 2.13$ & $21.50 \pm 1.81$ \\
\hline G & Induced $+40 \% \mathrm{PG}$ & $7.15 \pm 2.05$ & $22.58 \pm 2.91^{\#}$ & $7.32 \pm 2.05^{\#}$ & $14.30 \pm 1.45$ \\
\hline $\mathrm{H}$ & Induced $+20 \%$ PGW & $5.62 \pm 1.55$ & $22.58 \pm 2.72^{\#}$ & $4.88 \pm 2.08$ & $11.30 \pm 1.21^{\#}$ \\
\hline I & Induced $+40 \%$ PGW & $3.92 \pm 1.16$ & $20.97 \pm 1.71^{\#}$ & $3.66 \pm 1.09$ & $12.30 \pm 1.31^{\#}$ \\
\hline
\end{tabular}

Values represent mean \pm standard deviation $(n=6)$. Values with the symbol $\left({ }^{\#}\right.$ and $\left.{ }^{\# \#}\right)$ in the same column are significantly $(P<0.05)$ different induced diabetes group B. Values with the symbol $(*)$ in the same column are not significantly $(P<0.05)$ different from the normal control rat group. 
Effect of eggplant diets on plasma antioxidant status in diabetic rats: Additionally, as reported in Figure 5-10 and Table 1-2, endogenous antioxidant indices such as Vitamin C, Glutathione-S-transferase (GST), Glutathione peroxidase (GPx), reduced glutathione (GSH), catalase activity content were significantly $(\mathrm{P}<0.05)$ depleted in plasma of the diabetic rats (Group B) with a corresponding increased in pancreatic lipid peroxides produced when compared to the normal rats (Group A). Lipid peroxidation was assessed by measuring the formation of thiobarbituric acid-reactive substances (TBARS). However, treatment with diets supplemented with eggplants and metformin restored GST activity, GSH, GPx, Catalase, Vitamin C and reduced TBARS content to levels close to the normal range in the diabetic rats but Solanum kumba diet had the best output than the normal rats.

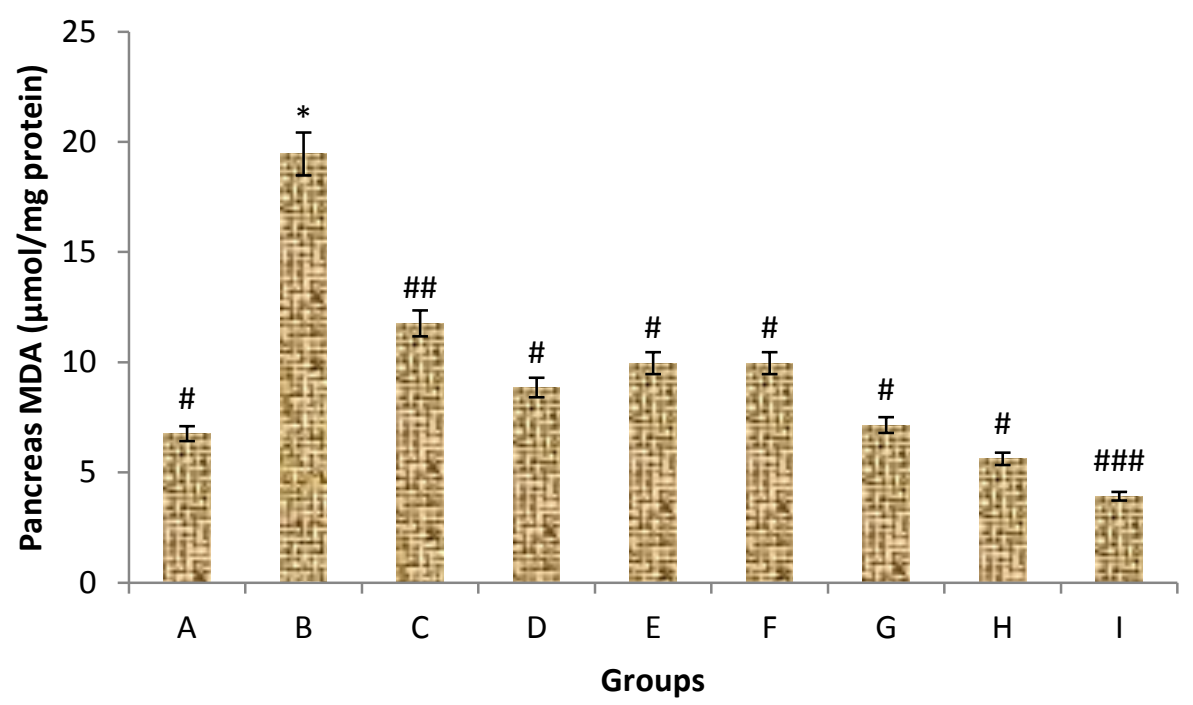

Figure 5. The effect of dietary Solanum spp on pancreatic lipid peroxidation MDA activity in type 2 diabetic rats. Values represent mean \pm standard deviation $(n=6)$. Bars with the same superscript symbol \# are not significantly different $(P<0.05)$. KEY: A: Control B: Induced with STZ C: Induced + Metformin D: Induced $+20 \%$ PW E: Induced $+40 \%$ PW F: Induced $+20 \%$ PGW G: Induced $+40 \%$ PGW H: Induced +20\% PG I: Induced + 40\% PG

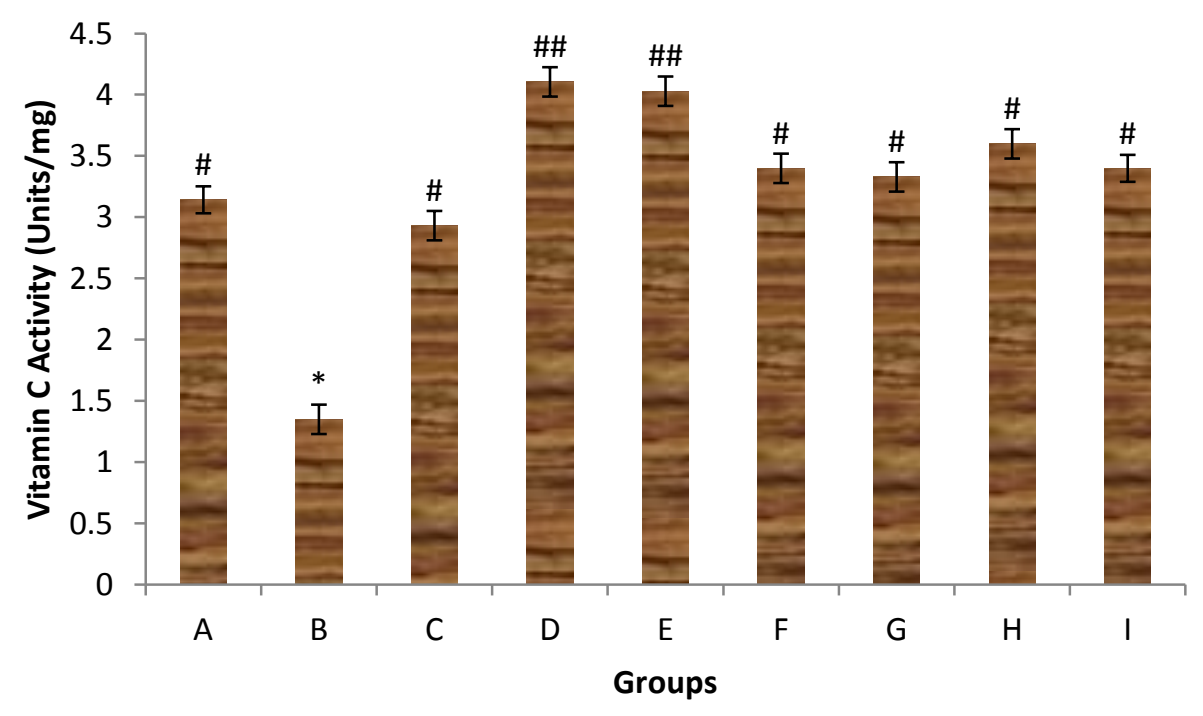

Figure 6. The effect of dietary Solanum spp on plasma vitamin C activity in type 2 diabetic rats. Values represent mean \pm standard deviation $(n=6)$. Bars with the same superscript symbol $(\#)$ are not significantly different $(P<0.05)$. KEY: A: Control B: Induced with STZ C: Induced + Metformin D: Induced $+20 \%$ PW E: Induced + 40\% PW F: Induced + 20\% PGW G: Induced + 40\% PGW H: Induced +20\% PG I: Induced + 40\% PG 


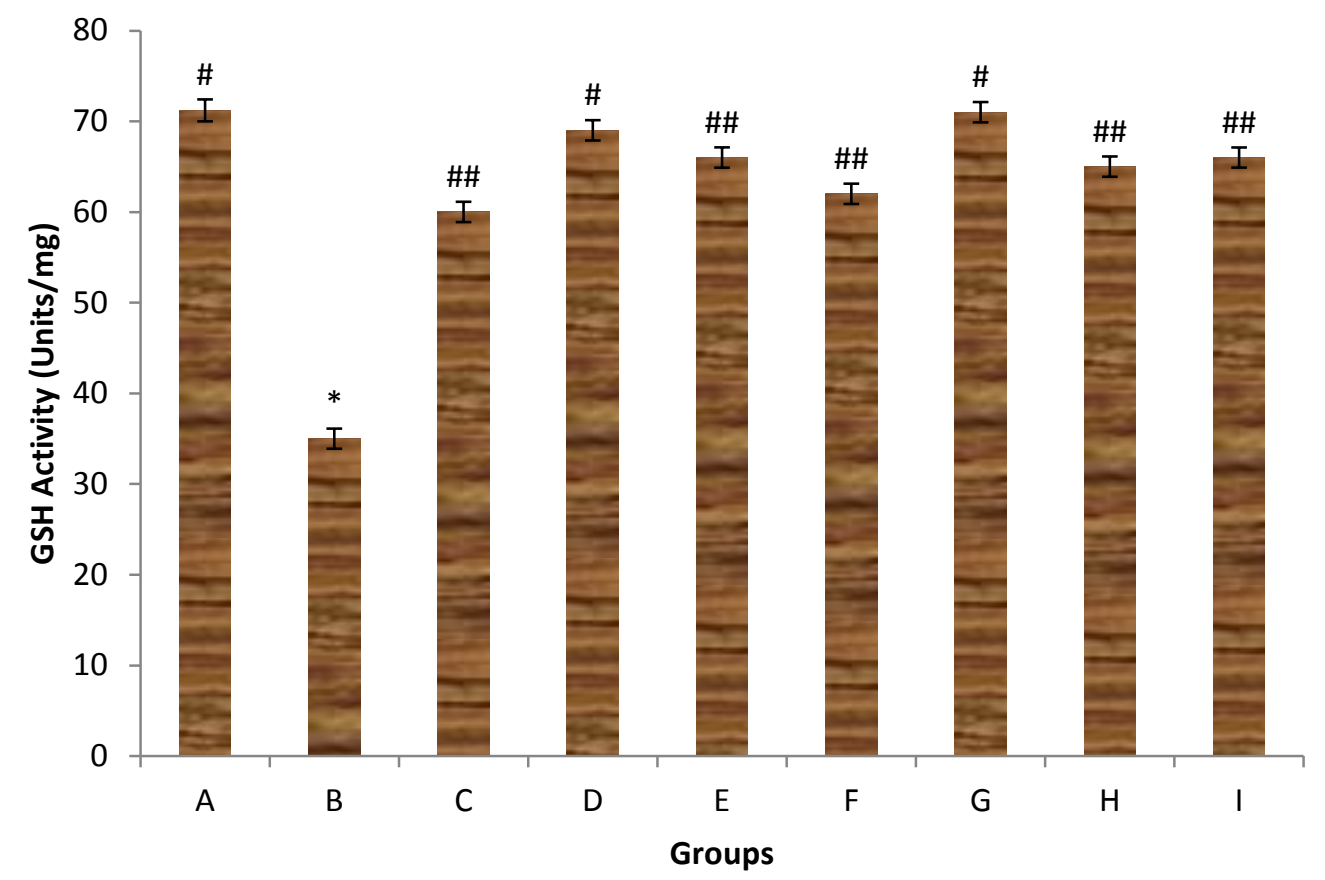

Figure 7. The effect of dietary Solanum spp on plasma GSH in type 2 diabetic rats. Values represent mean \pm standard deviation $(n=6)$. Bars with the same superscript symbol $\left({ }^{\#}\right)$ are not significantly different $(P<0.05)$. KEY: A: Control B: Induced with STZ C: Induced + Metformin D: Induced $+20 \%$ PW E: Induced $+40 \%$ PW F: Induced $+20 \%$ PGW G: Induced $+40 \%$ PGW H: Induced +20\% PG I: Induced + 40\% PG

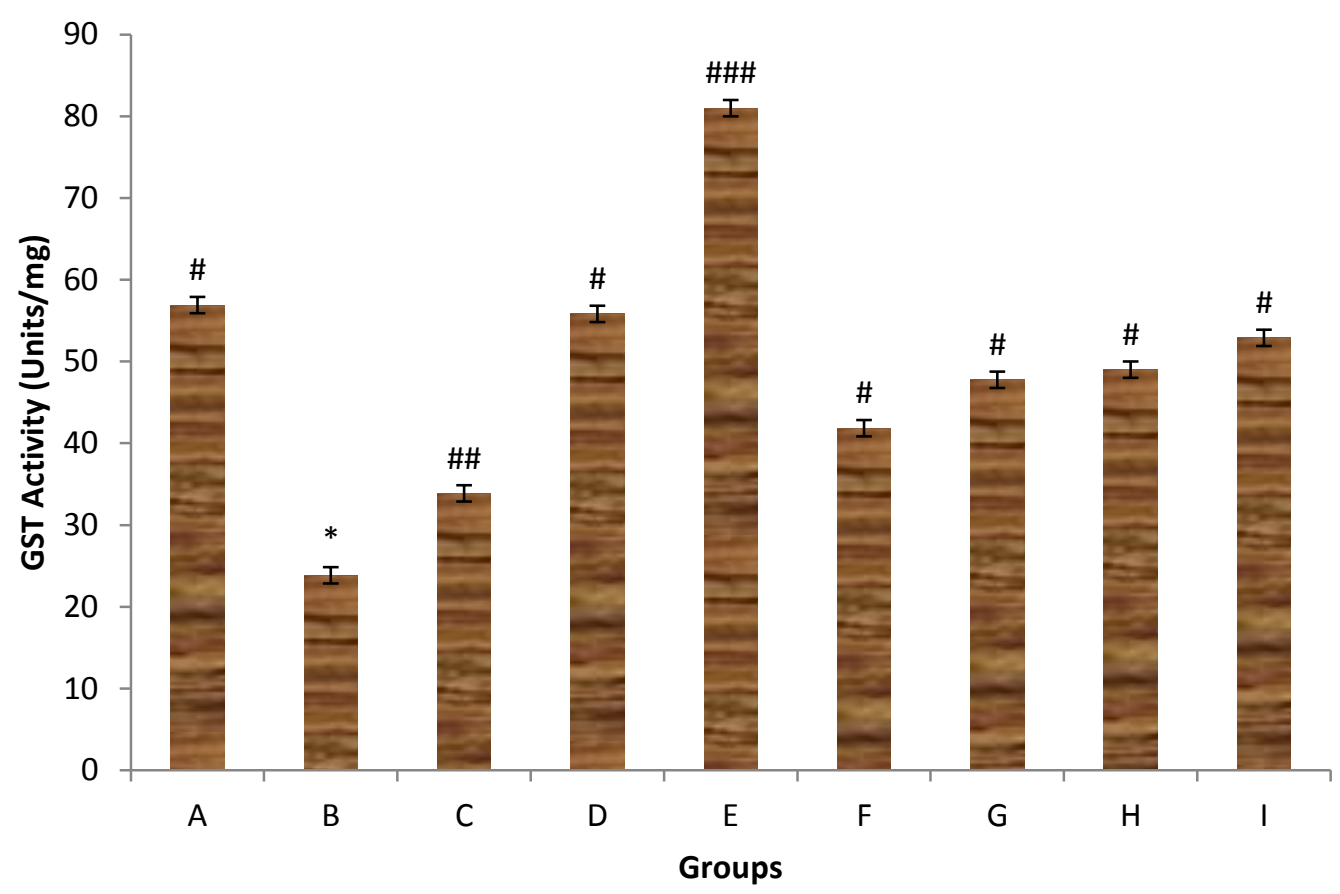

Figure 8. The effect of dietary Solanum spp on plasma GST activity in type 2 diabetic rats. Values represent mean \pm standard deviation $(n=6)$. Bars with the same superscript symbol $\left(^{\#}\right)$ are not significantly different $(P<0.05)$. KEY: A: Control B: Induced with STZ C: Induced + Metformin D: Induced $+20 \%$ PW E: Induced $+40 \%$ PW F: Induced $+20 \%$ PGW G: Induced $+40 \%$ PGW H: Induced +20\% PG I: Induced + 40\% PG 


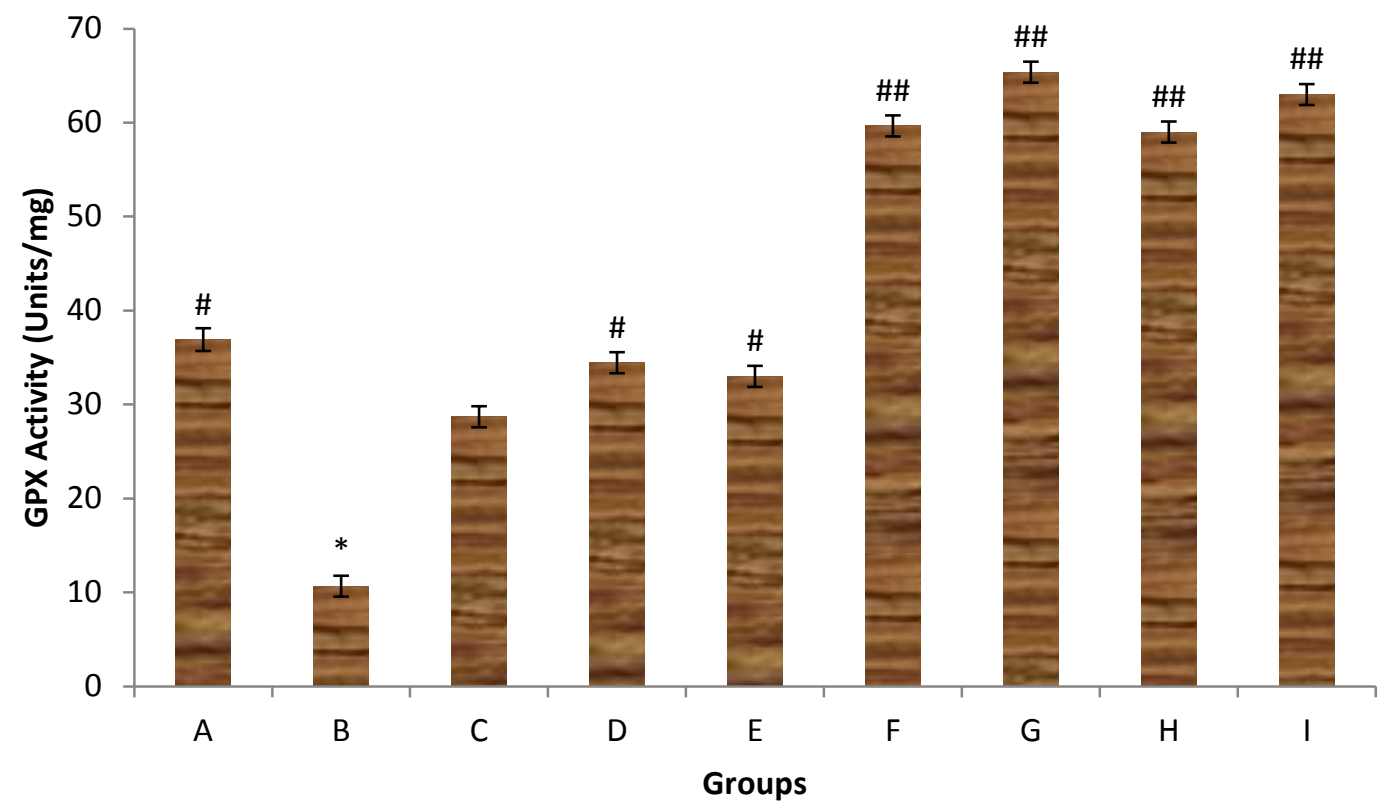

Figure 9. The effect of dietary Solanum spp on plasma GPX activity in type 2 diabetic rats. Values represent mean \pm standard deviation $(n=6)$. Bars with the same superscript symbol $\left(^{\#}\right)$ are not significantly different $(P<0.05)$. KEY: A: Control B: Induced with STZ C: Induced + Metformin D: Induced + 20\% PW E: Induced $+40 \%$ PW F: Induced $+20 \%$ PGW G: Induced + 40\% PGW H: Induced +20\% PG I: Induced + 40\% PG

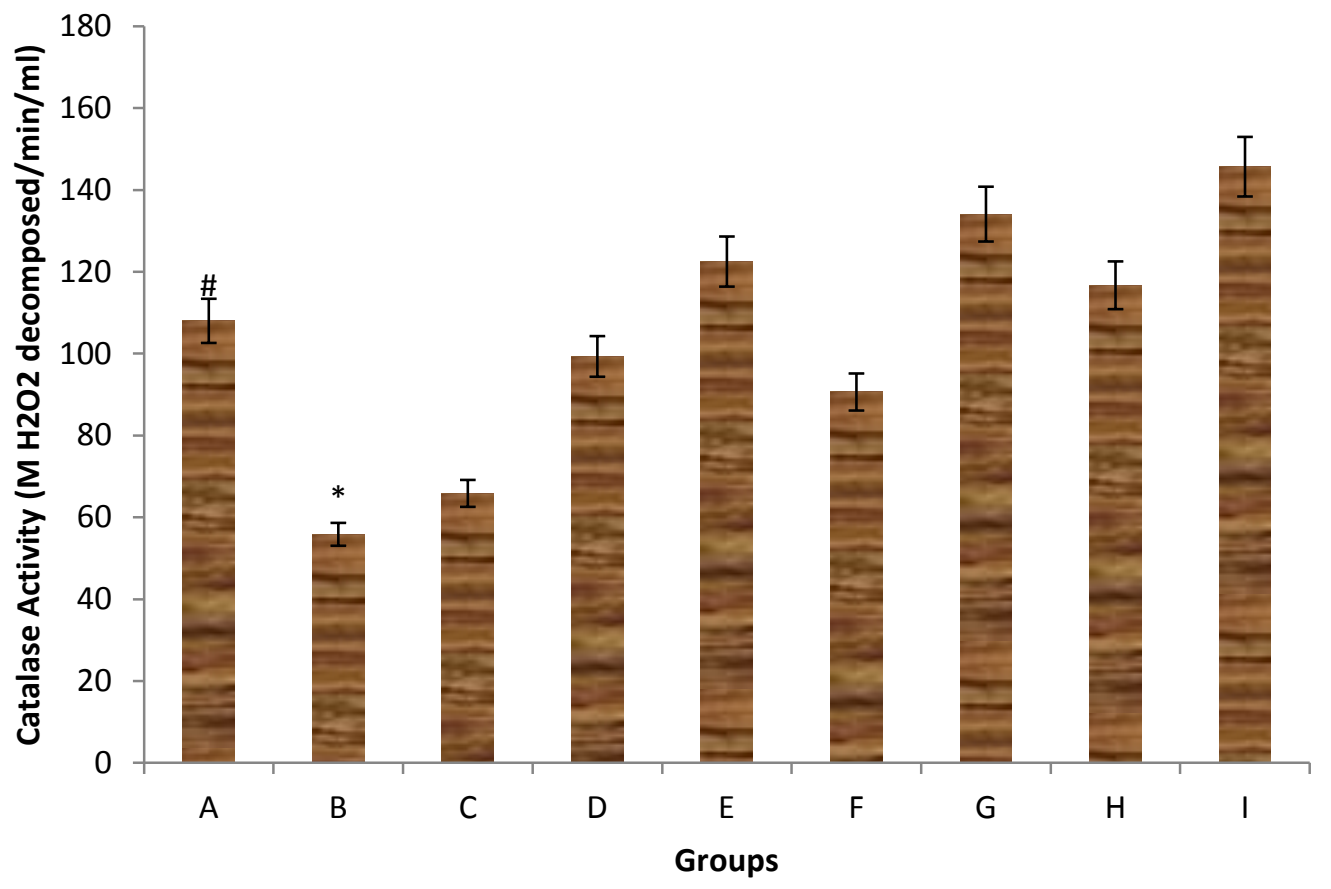

Figure 10. The effect of dietary Solanum spp on plasma catalase activity in type 2 diabetic rats. Values represent mean \pm standard deviation $(n=6)$. Bars with the same superscript symbol $\left(^{\#}\right)$ are not significantly different $(P<0.05)$. KEY: A: Control B: Induced with STZ C: Induced + Metformin D: Induced + 20\% PW E: Induced + 40\% PW F: Induced + 20\% PGW G: Induced + 40\% PGW H: Induced $+20 \%$ PG I: Induced $+40 \%$ PG. 
Table 2: The effect of dietary eggplant powder on the antioxidant status and enzymes in type-2 diabetic rats

\begin{tabular}{lllllll}
\hline Groups & Treatment & Vit C & GSH & GST & GPX & Catalase \\
& & $\begin{array}{l}\text { Units/mg } \\
\text { protein }\end{array}$ & $\begin{array}{l}\text { Units/mg } \\
\text { protein) }\end{array}$ & $\begin{array}{l}\text { Units/mg } \\
\text { protein }\end{array}$ & $\begin{array}{l}\text { Units/mg } \\
\text { protein }\end{array}$ & $\begin{array}{l}\text { Mol// } \mathrm{H}_{2} \mathrm{O}_{2} \\
\text { decomposed/min/L }\end{array}$ \\
\hline A & Basal(Control) & $3.14 \pm 0.11^{\#}$ & $71.2 \pm 2.61^{\# \#}$ & $56.89 \pm 3.41^{\#}$ & $36.90 \pm 2.02^{\#}$ & $107.98 \pm 5.13^{\#}$ \\
B & Induced STZ & $1.35 \pm 0.12$ & $35.01 \pm 2.40$ & $23.84 \pm 1.95$ & $10.66 \pm 1.04$ & $55.81 \pm 3.78$ \\
C & Induced+MET & $2.9 \pm 0.21$ & $60.05 \pm 3.50^{\#}$ & $33.84 \pm 1.40$ & $28.69 \pm 3.05$ & $65.81 \pm 5.81$ \\
D & Induced+20\%PW & $4.11 \pm 1.22^{\#}$ & $69.06 \pm 3.99^{\#}$ & $56.84 \pm 4.24^{\#}$ & $34.44 \pm 2.15^{\#}$ & $99.28 \pm 5.06$ \\
E & Induced+40\%PW & $4.03 \pm 1.18^{\#}$ & $66.09 \pm 3.79^{\#}$ & $55.80 \pm 4.23^{\#}$ & $32.99 \pm 2.10^{\#}$ & $122.47 \pm 6.24^{\#}$ \\
F & Induced+20\%PG & $3.40 \pm 1.98^{\#}$ & $62.05 \pm 3.68^{\#}$ & $41.83 \pm 4.01^{\# \#}$ & $59.64 \pm 1.98^{\# \#}$ & $90.59 \pm 5.22$ \\
G & Induced+40\%PG & $3.33 \pm 1.88^{\#}$ & $71.01 \pm 4.01^{\# \#}$ & $47.75 \pm 3.99^{\# \#}$ & $65.36 \pm 4.25^{\# \#}$ & $134.06 \pm 6.47^{\#}$ \\
H & Induced+20\%PGW & $3.60 \pm 1.23^{\#}$ & $65.01 \pm 3.98^{\#}$ & $48.99 \pm 4.03^{\# \#}$ & $58.99 \pm 3.01^{\# \#}$ & $116.67 \pm 6.11^{\#}$ \\
I & Induced+40\%PGW & $3.40 \pm 1.18^{\#}$ & $66.01 \pm 3.78^{\#}$ & $52.88 \pm 4.25^{\#}$ & $62.98 \pm 1.56^{\# \#}$ & $145.66 \pm 7.11^{\#}$ \\
& & & & & & \\
\hline
\end{tabular}

Values represent mean \pm standard deviation $(n=6)$. Values with the symbol $\left({ }^{\#}\right.$ and $\left.{ }^{\# \#}\right)$ in the same column are significantly $(P<0.05)$ different induced diabetes group B. Values with the symbol $\left(^{\#}\right)$ in the same column are not significantly $(P<0.05)$ different from the normal control rat group.

Chromatographic fingerprint evaluation of the different species of the eggplant: HPLC fingerprinting of eggplant extract using reverse-phase HPLC-DAD is presented in Fig. 11-13. Extracts of Solanum spp revealed the presence of some phenolic acids and flavonoids (Table 3). Amongst these phenolic constituents Gallic acid, Chlorogenic acid, caffeic acid, Ellagic acid, Rutin, Quercitrin, and Quercetin were present as major phenolic compounds, while Catechin, Epicatechin, Kaempferol were relatively available as minor phenolic compounds (Table 3), except Isoquercitrin present in Solanum aethiopicum. Some phenolics were not detected that was present in other sample species. The phenolics in Table 3 were identified and quantified through their retention times and UV spectra (Figure 11-13).

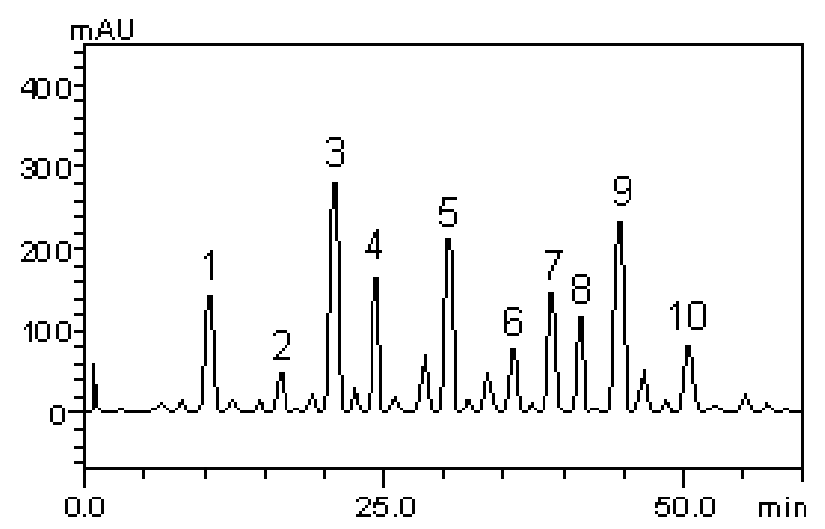

Figure 11: Representative high performance liquid chromatography profile of Solanum kumba (PG) Gallic acid (peak 1), catechin (peak 2), chlorogenic acid (peak 3), caffeic acid (peak 4), ellagic acid (peak 5), epicatechin (peak 6), rutin (peak 7), quercitrin (peak 8), quercetin (peak 9) and kaempferol (10). 


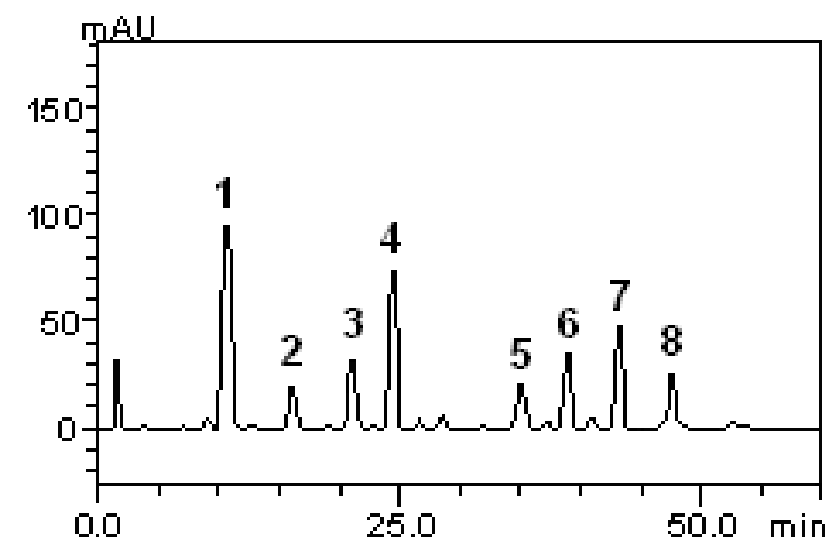

Figure 12: Representative high performance liquid chromatography profile of Solanum aethiopicum (PGW) extract. G allic acid (peak 1), catechin (peak2), chlorogenic acid (peak 3), caffeic acid (peak 4), epicatechin (peak 5), rutin (peak 6), isoquercitrin (peak 7) and quercetin (peak 8).

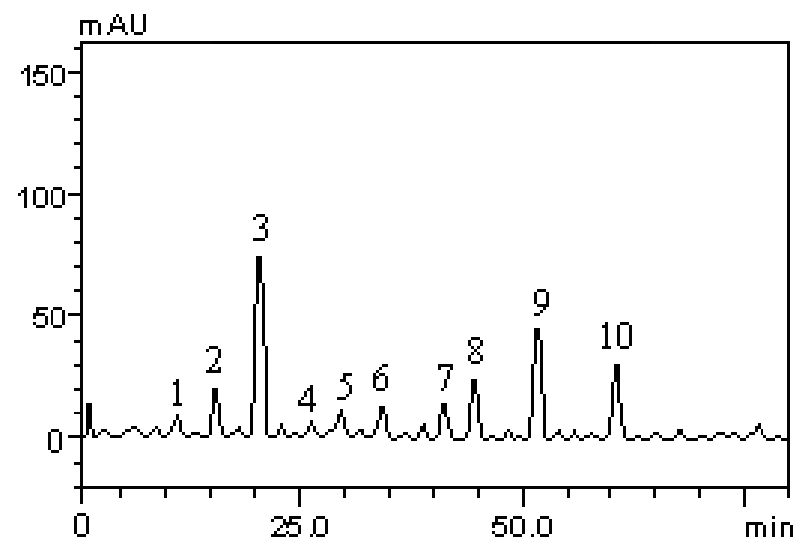

Figure 13: Representative high performance liquid chromatography profile of Solanum gilo (PW). Gallic acid (peak 1), catechin (peak 2),chlorogenic acid (peak 3), caffeic acid (peak 4), ellagic acid (peak 5), epicatechin (peak 6), rutin (peak 7), quercitrin (peak 8), quercetin (peak 9) and kaempferol (peak 10).

Table 3: Phenolic composition of garden egg species using HPLC-DAD analysis

\begin{tabular}{|c|c|c|c|}
\hline Samples & $\begin{array}{l}\text { PG } \\
(\text { S.kumba) }\end{array}$ & $\begin{array}{l}\text { PGW } \\
\text { (S.aethiopicum) }\end{array}$ & $\begin{array}{l}\text { PW } \\
\text { (S.gilo) }\end{array}$ \\
\hline Compounds & $\mathrm{mg} / \mathrm{g}$ & $\mathrm{mg} / \mathrm{g}$ & $\mathrm{mg} / \mathrm{g}$ \\
\hline Gallic acid & $17.36 \pm 0.02^{\mathrm{a}}$ & $50.34 \pm 0.01^{\mathrm{a}}$ & $2.73 \pm 0.01^{\mathrm{a}}$ \\
\hline Catechin & $4.25 \pm 0.01^{b}$ & $12.67 \pm 0.02^{b}$ & $5.39 \pm 0.01^{b}$ \\
\hline Chlorogenic acid & $30.81 \pm 0.01^{\mathrm{c}}$ & $20.71 \pm 0.01^{\mathrm{c}}$ & $20.67 \pm 0.03^{c}$ \\
\hline Caffeic acid & $19.76 \pm 0.03^{\mathrm{d}}$ & $39.46 \pm 0.03^{\mathrm{d}}$ & $2.15 \pm 0.01^{\mathrm{d}}$ \\
\hline Ellagic acid & $25.13 \pm 0.03^{\mathrm{e}}$ & ND & $2.93 \pm 0.02^{\mathrm{a}}$ \\
\hline Epicatechin & $6.32 \pm 0.01^{\mathrm{f}}$ & $14.53 \pm 0.02^{b}$ & $3.12 \pm 0.03^{\mathrm{a}}$ \\
\hline Rutin & $16.89 \pm 0.03^{a}$ & $22.18 \pm 0.01^{\mathrm{c}}$ & $4.98 \pm 0.01^{\mathrm{b}}$ \\
\hline Quercitrn & $12.45 \pm 0.01^{\mathrm{g}}$ & ND & $6.17 \pm 0.03^{b}$ \\
\hline Quercetin & $26.47 \pm 0.02^{e}$ & $14.92 \pm 0.03^{b}$ & $12.58 \pm 0.01^{\mathrm{e}}$ \\
\hline Kaempferol & $7.08 \pm 0.03^{f}$ & ND & $10.92 \pm 0.03^{f}$ \\
\hline Isoquercitrin & ND & $28.36 \pm 0.01^{\mathrm{e}}$ & ND \\
\hline
\end{tabular}

Results are expressed as mean \pm standard deviations (SD) of three determinations. Averages followed by different letters differ by Tukey test at $\mathrm{p}<0.01$ ND... NOT DETECTED 


\section{DISCUSSION}

Streptozotocin is a nitrosourea analogue, preferentially uptaken by pancreatic beta cells via GLUT 2 glucose transporter and causes DNA alkylation followed by the activation of poly ADP ribosylation leading to depletion of cytosolic concentration of $\mathrm{NAD}^{+}$and ATP. Enhanced ATP dephosporylation after STZ treatment provides substrate for xanthine oxidase resulting in the formation of superoxide radicals. Furthermore, NO moiety is liberated from STZ leading to the destruction of $\beta$ cells by necrosis. Thus, STZ-induced experimental diabetes was used on the animal for the present study [22]. Phytochemicals are bioactive compounds (secondary metabolites) found in fruits and plants that work synergistically with nutrients and dietary fibers to protect against diseases [23]. Most plants with antidiabetic properties have been found to contain secondary metabolites such as glycosides, alkaloids, phenols and flavonoids etc. [24]. It has been demonstrated that many plants/fruits exhibit efficient antioxidant properties owing to their phenolic constituentsPrevious studies on eggplant/gardenegg fruits showed the presence of alkaloids, flavonoids, tannins, and phenols [9, 25].

Blood glucose is an index for the diagnosis of diabetes mellitus. Hyperglycemia is an important factor in the development and progression of the complications of diabetes mellitus [24 ]. In this study, diabetic rats showed elevation in blood glucose level as a result of interperitional administration of streptozotocin but supplementation with eggplant diet resulted in a significant reduction of blood glucose levels indicating the antihyperglycemic nature of the eggplant as a result of the phenolics and flavonoids present as depicted in the Hplc/Dad charactarization which also agrees with the invitro studies reported $[9,24]$ on these eggplant. Cardiovascular diseases are important complications of DM [26]. Renin produces Angiotensin-I from angiotensinogen, which is later converted to Angiotensin-II (a potent vasoconstrictor) by Angiotensin-I converting enzyme (ACE). Angiotensin-II has been implicated as a major factor in hypertension and other diabetic cardiovascular complications. ACE inhibitors have been developed to inhibit Angiotensin- II production in cardiovascular diseases. As revealed in this study, the significant increased in ACE activity observed in diabetic control rats (Group B) compared to normal rats (Group A) could be attributed either to (i) increased glycosylation of important enzymes/proteins and leading to altered expression of genes responsible for the regulation of the renin-angiotensin system, (ii) hyperglycemiainduced ROS production and (iii) hyperglycemia induced-deranged lipid metabolism in diabetic conditions. ROS are the main mediators of cellular damage in diabetes and may also act as a transduction signal for Angiotensin- II in different cell types, like smooth muscle cells, endothelial cells and human ventricular myocytes. Furthermore, findings have demonstrated a positive correlation between hypercholesterolemia and synthesis of angiotensin peptides [26]. However, the reduced ACE activity observed in the diets supplemented with eggplant may be attributed to the bioavailability of their polyphenolic compounds with potent antioxidant and ACE inhibitory properties and/or antihyperglycemic effect of the eggplants. Current research has revealed that polyphenols possess strong ACE inhibitory activity and may be relevant in the treatment of hypertension in both diabetic and non-diabetic patients [9].

Persistent hyperglycemia causes increased oxidative stress, which contributes to the development and progression of most of the diabetes-associated complications. Having evolved in an oxygen environment, most cells - including pancreatic beta-cells - have acquired intricate mechanisms to defend against ROS toxicity. However, the reduced antioxidant 
capacity potentially makes pancreatic $\beta$-cells sensitive to ROS mediated signal transduction and cellular response. Therefore, maintenance of $\beta$-cell oxidant status and their protection against oxidative damage might delay the onset of diabetes, as well as the progression of its complications [27]. Mammalian cells are equipped with both enzymatic and non-enzymatic antioxidant defences to minimize the cellular damage caused by interaction between cellular constituents and oxygen free radicals [28]. Oxygen free radicals are generated as by products of normal cellular metabolism. However, several conditions are known to disturb the balance between oxygen free radicals production and cellular defence mechanisms. This imbalance can result in cell dysfunction and destruction resulting in tissue injury. The increase in the level of oxygen free radicals in diabetes may be due to their increased production and or decreased destruction by non-enzymatic and enzymatic catalase, glutathione peroxidase (GSH-Px), and superoxide antioxidants.

During diabetes, persistent hyperglycaemia causes increased production of oxygen free radicals from glucose autoxidation [29] and protein glycosylation [30]. The level of these antioxidant enzymes critically influences the susceptibility of various tissues to oxidative stress and is associated with the development of complications in diabetes [27]. Pancreatic $\beta$-cell death which underlies type 2-diabetes may occur via immune or non-immune mechanisms. Pancreatic $\beta$-cell lysis by cytotoxic T-lymphocytes and cytokine-mediated lysis by macrophages and helper T-cells through oxygen free radical-mediated mechanisms are well documented [27, 28]. Streptozotocin (STZ) stimulates $\mathrm{H}_{2} \mathrm{O}_{2}$ generation invitro as well as invivo in pancreatic $\beta$ cells, which thereby results in DNA fragmentation. However, supplementation with the eggplant diet ameliorates the effect of these radicals, as a result of the polyphenols present in the eggplant supplemented diets. The HPLC quantification revealed there were variations in the individual amount of the polyphenols present in Solanum aethiopicum and Solanum Kumba; unlike Solanum gilo which have the least amount of polyphenols, this variation could be responsible for the biological activities observed from the study. A previous report [9] demonstrated that Solanum aethiopicum has the highest invitro activities followed by Solanum Kumba. However, this invivo study demonstrated otherwise, which could be due to the variation in the phenolics and flavonoids present.

\section{CONCLUSION}

The study revealed the antidiabetes, antihypertensive and antioxidant properties of tropical eggplant supplemented diets in experimental type 2 diabetic animal model. These therapeutic effects could be attributed to the $\alpha$-amylase, $\alpha$-glycosidase and ACE inhibitory properties of constituent polyphenols of the eggplant.

Competing Interests: The authors have no conflict of interest.

Author's Contributions: All authors contributed to this study.

\section{Acknowledgement}

The Author acknowledges the Staff Development Support of the Federal University of Technology Akure, Nigeria. 


\section{REFERENCES}

1. Group DCCTR. 1995.The relationship of glycemic exposure (HbA1c) to the risk of development and progression of retinopathy in the Diabetes Control and Complications Trial. Diabetes 44: 968-983.

2. Fowler MJ.2008. Microvascular and macrovascular complications of diabetes. Clin Diabetes 26: 77

3. Rohlfing CL, Wiedmeyer H-M, Little RR, England JD,Tennill A Goldstein DE. 2002. Defining the relationship between plasma glucose and HbA1c analysis of glucose profiles and HbA1c in the Diabetes Control and Complications Trial. Diabetes Care 25: 275-278.

4. Zoungas S, Chalmers J, Ninomiya T, Li Q, Cooper M, Colagiuri S, Fulcher G, De Galan B, Harrap S Hamet P. 2012 .Association of HbA1c levels with vascular complications and death in patients with type 2 diabetes: evidence of glycaemic thresholds. Diabetologia 55: 636-643.

5. Dinneen SF. 2010 What is Diabetes? Medicine; 38: 589 -591.

6. Nwanna EE, Ibukun EO, Oboh G, 2013 Nutritional contents and antioxidant activities of african garden egg (Solanum aethiopium) species. Adv.Food Sci. 35: 1.

7. American Diabetes Association,2009.Diagnosis and classification of diabetes mellitus. Diabetes Care. 32: S62-S67.

8. Centres for Disease Control and Prevention (CDC): 1998. National Diabetes fact sheet National estimates and general information on diabetes in the United States Atlanta G.N HHS.

9. Nwanna E.E; Ibukun, E.O; Oboh G;Ademosun, A.O;Boligon A.A; Athayde M.2014 HPLC-DAD Analysis and In-Vitro Property of Polyphenols Extracts from (Solanum Aethiopium) Fruits on $\alpha$-Amylase, $\alpha$-Glucosidase and Angiotensin -1- Converting Enzyme Activities Int J Biomed Sci ; 10 (4): 272-281.

10. Oboh $\mathrm{G}$ and Ogunruku OO,2010 Cyclophosphamide-induced oxidative stress in brain: protective effect of hot short pepper (Capsicum frutescens L. var. abbreviatum). Exp Toxicol Pathol 62:227-233

11. 11.Srinivasan K, Viswanad B, Asrat L, Kaul CL and Ramarao P. 2005 Combination of high-fat diet-fed and low-dose streptozotocin-treated rat: a model for type-2 diabetes and pharmacological screening. Pharmacol Res 52:313-320

12. Zhang M, Lv XY, Li J, Xu Z.G, Chen,L. 2008.The characterization of high-fat diet and multiple low-dose streptozotocin induced type 2 diabetes rat model, Exp. Diabetes Res.704045 9, http://dx.doi.org/10.1155/2008/704045.

13. Ohkawa,H Ohishi,N,Yagi,K 1979 Assay for lipid peroxides in animal tissues by thiobarbituric acid reaction, Anal. Biochem. 95 351-358.

14. Mannervik,B Guthenberg,C 1981. Glutathione transferase (human placenta), Meth Enzymol 77 231-235.

15. Ellman, GL; 1959. Tissue sulfhydryl groups, Arc Biochem Biophys 82 70-77.

16. .K. Worthington ;Worthington V, 1993 Alpha amylase, in:Worthington Enzyme Manual, Worthington Biochemical Corp, Freehold, NJ,pp. 36-41.

17. .Apostolidis,A Kwon,YI and Shetty K 2007. Inhibitory potential of herb, fruit, and fungal enriched cheese against key enzymes linked to type 2 diabetes and hypertension,Innov Food Sci Emerg Technol 8 46-54. 
18. Cushman, DW. Cheung,HS. 1971.Spectrophotometric assay and properties of the angiotensin I-converting enzyme of rabbit lung, Biochem. Pharmacol. 20 1637-1648.

19. Amaral GP, Carvalho NR, Barcelos RP, et al. 2013.Protective action of ethanolic extract of Rosmarinus officinalis L.in gastric ulcer prevention induced by ethanol in rats. Food Chem. Toxi. 55: 48-55.

20. Sabir SM, Ahmad SD, Hamid A, et al. 2012.Antioxidant and hepatoprotective activity of ethanolic extract of leaves of Solidago microglossa containing polyphenolic compounds. Food Chem. p741-747.

21. Zar JH. 1984.Biostatistical Analysis. New Jersey: Prentice-Hall. ISBN0-13-081542X 620 .

22. Szkudelski T, 2001 Physiol Res 50, 537-546.

23. Craig,W Beck, L 1999 Can J Diet Pract Res, , 60(2), 78-84.

24. Kwon YI, Apostolidis E Sheffy K. 2008. In-vitro studies of eggplant. Biores.Tech.; 99: 2981-2988.

25. Nwanna EE, Ibukun EO, Oboh G. 2013. Antioxidative properties and inhibition of some pro-oxidant induced lipid peroxidation by aqueous extract of two species of eggplants Solanum macrocarpon and Solanum melongena. J. Nut. Met.; 5 (5): 8897.25 .

26. Horan,MJ.1984. Diabetes and hypertension, National Diabetes Data Group: Diabetes in America: Diabetes Data CompiledUS Dept of Health and Human Services, Publication No. (NIH) p. 1468.

27. Daugherty,A; Rateri,DL;Lu,H; Inagami,T; Cassis,L.A2004.Hypercholesterolemia stimulates angiotensin peptide synthesis and contributes to atherosclerosis through the AT1A receptor, Circulation 110 3849-3857.

28. Freeman BA, Crapo JD. 1982. Biology of disease. Free radicals and tissue injury. Lab Invest 47: 412-26.

29. Hunt JV,Smith CCT,Wolff SP. 1990.Autoxidative glycosylation and possible involvement of peroxides and free radicals in LDL modification by glucose. Diabetes 39: $1420 \pm 4$.

30. Wolff SP, Dean RT. 1987 Glucose autoxidation and protein modi®cation: the potential role of autoxidative glycosylation in diabetes. Biochem J 245:243-50. 